\title{
Correction to: Emotional intimacy and sexual well-being in aging European couples: a cross-cultural mediation analysis
}

\author{
Aleksandar Štulhofer ${ }^{1}$ (D ) Tanja Jurin ${ }^{2} \cdot$ Cynthia Graham ${ }^{3} \cdot$ Erick Janssen $^{4} \cdot$ Bente Træen $^{5}$
}

Published online: 19 May 2020

(c) Springer Nature B.V. 2020

Correction to: European Journal of Ageing (2020) 17:43-54
https://doi.org/10.1007/s10433-019-00509-x

\begin{abstract}
Sexual health research tends to focus on problematic aspects of sexuality. This also applies to research on sexuality in older men and women, where attention has been primarily on the negative impact of aging. To contribute to the emerging interest in positive (successful) sexual aging, we aimed to: (1) further validate a recently developed 5-dimensional measure of sexual well-being (Štulhofer et al. in J Sex Res, 2018. https://doi.org/10.1080/00224499.2018.1456510) and (2) explore the structure of associations among emotional intimacy, frequency of sexual intercourse, and sexual well-being in older European couples. Using data from a 2016 community-based survey of 218 Norwegian, 207 Danish, 135 Belgian, and 117 Portuguese couples aged 60-75 years, we applied actor-partner interdependence structural modeling approach to confirm the validity of the sexual well-being measure in couples and explore a path analytic model in which the frequency of sexual intercourse was hypothesized to mediate the association between emotional intimacy and sexual well-being. Although we observed consistent and significant actor effects, with emotional intimacy and frequency of sexual intercourse predicting both male and female partners' sexual well-being across countries, the proposed mediation was observed only in Norwegian and Portuguese men and Norwegian and Belgian women. Partner effects were gender-specific; male partner's emotional intimacy was related to his female partner's reported frequency of sex and sexual well-being but not the other way around. Apart from being one of the few cross-cultural assessments of successful sexual aging, this study's findings support the use of a new sexual well-being measure in research on older adults' sexuality.
\end{abstract}

Keywords Aging $\cdot$ Sexual well-being $\cdot$ Intimacy $\cdot$ Sexual activity $\cdot$ Couples $\cdot$ APIM

Responsible editors: F. Villar (guest editor) and M.J. Aartsen.

For reason beyond the control of the authors or the editors, the article titled "Emotional intimacy and sexual well-being in aging European couples: a cros-cultural mediation analysis" by Aleksandar Štulhofer ${ }^{1} \cdot$ Tanja Jurin $^{2} \cdot$ Cynthia Graham ${ }^{3} \cdot$ Erick Janssen $^{4}$ - Bente Træen ${ }^{5}$ (https://doi.org/10.1007/s10433-01900509-x) was published in the regular issue Vol. 17 issue 1 instead of this special section, where it was originally scheduled to appear. Therefore, the full article is reprinted here.

The original article can be found online at https://doi.org/10.1007/ s10433-019-00509-x.

Aleksandar Štulhofer

astulhof@ffzg.hr

1 Department of Sociology, Faculty of Humanities and Social Sciences, University of Zagreb, I. Lučića 3, 10000 Zagreb, Croatia

2 Department of Psychology, Faculty of Humanities and Social Sciences, University of Zagreb, Zagreb, Croatia

3 Department of Psychology, Centre for Sexual Health Research, University of Southampton, Southampton, England, UK

4 Department of Neurosciences, Institute for Family and Sexuality Studies, University of Leuven, Louvain, Belgium

5 Department of Psychology, University of Oslo, Oslo, Norway 


\section{Introduction}

Traditionally, sexual health research tends to focus on problematic aspects of sexuality and sexual behavior, including sexual risk-taking and sexual problems and their treatment. This seems to apply in spades to research on sexuality in older men and women, where attention has primarily been on the negative impact of aging on sexual function (Syme et al. 2018). More recently, however, there has been increased interest in positive aspects of sexuality, such as sexual well-being (Graf and Patrick 2014), sexual wellness (Syme et al. 2018), and sexual satisfaction (Neto 2012; Pascoal et al. 2014). Several definitions of sexual well-being have been put forward, but most include both affective and cognitive dimensions related to the perceived quality of an individual's sexuality, sexual life, and relationships (Rosen and Bachmann 2008; Neto 2012; Graf and Patrick 2014).

While the increased attention to positive aspects of sexuality is a welcome development, the focus on sexual function and sexual activity that characterizes research on sexual well-being may be problematic in the context of aging. For example, Rosen and Bachmann (2008) operationalized sexual well-being in terms of sexual function, interest, and satisfaction. This narrow focus on sexual function and activity is limiting for several reasons. First, while older men and women are more likely than younger individuals to report sexual function problems (Mitchell et al. 2013; Hendrickx et al. 2015; Peixoto and Nobre 2015), distress associated with such problems may be low (Bancroft et al. 2003; Lee et al. 2016; Santos-Iglesias et al. 2016). Secondly, studies have suggested that for many older adults, physical closeness and intimacy may be more important than sexual activity per se (Sandberg 2013; Müller et al. 2014; Lee et al. 2016; Fileborn et al. 2017; Freak-Poli et al. 2017). Based on findings from a large study of midlife and older adults' definitions of sexual wellness, Syme et al. (2018) concluded that conceptualizing and measuring sexual wellness in this population requires a multidimensional approach that includes psychological, social, and attitudinal aspects in addition to sexual function and activity-related ones. Thus, the limited research that exists in this area highlights the importance of conceptualizing sexual well-being differently for older adults.

It should be noted that most measures of sexual wellbeing have been validated in individuals with sexual problems (e.g., Costa et al. 2003; Abraham et al. 2008; Rosen et al. 2009) and many were developed using only samples of female participants, often premenopausal women (Öberg et al. 2002; De Visser et al. 2007; Rosen et al. 2009; Stephenson et al. 2010; Muise et al. 2010; Bancroft et al. 2011; Anderson et al. 2016). As yet, no existing measure of sexual well-being has been validated in older adults.
Using a population-based sample of older individuals $(60+)$ from four European countries (Štulhofer et al. 2018), we have developed and validated a multidimensional measure of sexual well-being in older adults. The measure includes five dimensions: physical intimacy, emotional closeness during sex, sexual compatibility, sexual satisfaction, and distress related to sexual function problems. In support of its convergent validity, we found that the wellbeing measure was significantly and positively associated with emotional intimacy and frequency of sexual intercourse and negatively with masturbation (Štulhofer et al. 2018).

In the current study, we attempted to validate the new measure in a cross-cultural dyadic sample and explore structural associations among emotional intimacy, the frequency of sexual activity, and sexual well-being in a multi-country sample of older couples. The study has a potential to inform health professionals working with older population about the structure of sexual well-being, as well as the roles of emotional intimacy and sexual intercourse in aging European couples' sexual well-being.

\section{Emotional intimacy and sexuality in aging men and women}

A number of studies have highlighted the importance of emotional intimacy for aging individuals' sexuality (Laumann et al. 2006; Sandberg 2013; Müller et al. 2014; Fileborn et al. 2017). In a longitudinal population-based study of aging German men and women, participants in the highest age group (74 years) prioritized "affection" over sexual activity. In the Australian Sex, Age, and Me study (Fileborn et al. 2017), qualitative interviews with individuals aged 60 and older revealed that both men and women considered intimacy and bonding a central component of their sexual lives.

\section{Aging and the frequency of sexual activity}

While not all older adults are engaging in partnered sexual activity (in many cases because they do not have a partner (Træen et al. 2017), many mid- and later life adults do remain sexually active (Lindau et al. 2007; Waite et al. 2009; DeLamater 2012; Wang et al. 2015). Research indicates that for the majority of older adults, sex remains important to their quality of life and is considered a central element of a satisfying relationship (Fisher et al. 2010).

In a review of the literature on factors associated with sexual well-being in older adults, Kleinstäuber (2017) noted that the links between sexual activity and sexual well-being are variable and complex. Different operationalizations of sexual activity likely contribute to this situation. In another review, involving 57 studies on sexual activity in adults at least 60 years old, Bell et al. (2017) noted an "overwhelming focus on intercourse" (p. 21). However, older adults may 
focus more on other types of sexual behavior (Lindau et al. 2007; Fisher et al. 2010; Trudel et al. 2014) which suggests that older couples' sexual activity is underestimated when it is evaluated solely by measuring the frequency of sexual intercourse.

\section{Emotional intimacy and sexual activity}

Evidence supporting the importance of closeness, affection, and emotional intimacy during sexual activity in older adults mainly-although not exclusively (see Heiman et al. 2011) — comes from qualitative studies. In a qualitative study with 30 men and women aged $60-82$ years, a factor labeled "depth" contributed to "optimal" sexual experiences (Ménard et al. 2015). Depth referred to "the connection, the intimacy, the love, the caring and the levels of trust, safety and communication that they felt with their partners" (Ménard et al. 2015, p. 87). While the importance of emotional intimacy during sex has been most often studied in women, several recent studies also highlight the importance of emotional intimacy for older men's sexuality. These studies challenge the idea that intimacy for men is either arduous or unimportant and that male sexuality is firmly tied to the ability to perform during intercourse and to reach orgasm (Sandberg 2013). For example, Fileborn et al. (2017) found that Australian men aged 60+, when asked about the importance of sex, frequently indicated that sexual activity plays a vital role in emotional bonding and maintaining intimacy with a partner. Partnered sexual activity was described as offering higher levels of intimacy and closeness than platonic relationships could provide. In interviews, Swedish heterosexual men aged 67-87 years described intimacy as something "more or other than sexual intercourse," including touching, feelings of love, and emotional closeness in a committed relationship (Sandberg 2013). Older men also recounted how the importance of intimacy had increased with age. While their sexual activity at younger ages used to be much more focused on penetrative sex, at the time of the interview it was primarily experienced through sensual touch and intimacy (Sandberg 2013).

Studies involving mixed-age samples also demonstrated the importance of emotional intimacy and closeness during sex. In a US study of women aged 20-65 years, one of the strongest (negative) predictors of distress about their sexual relationship was how emotionally close women felt to their partner during sexual activity (Bancroft et al. 2003). Murray et al. (2017) interviewed men aged 30-65 years in long-term relationships, who discussed how intimate communication with their partner sometimes "sparked" closeness and could lead to sexual activity. In a focus group study of men aged
18-70 years, some participants described how an emotional connection with their partner could positively impact, and sometimes be key to, the experience of sexual arousal during partnered sex (Janssen et al. 2008).

\section{Dyadic approach}

In recent years, researchers in the area of romantic relationships have started to apply dyadic approaches (e.g., Muise et al. 2018). In contrast to traditional individual-based approaches, dyadic approaches use the couple as the unit of analysis and allow for a more realistic assessment of (interdependent) perceptions, beliefs, and behaviors, including those relevant to aging men's and women's sexual wellbeing. For example, Bell et al. (2017) found decreased sexual activity in individuals over 60 years of age to be strongly associated with the partner's sexual and other physical health problems. These findings underscore the importance of looking beyond individual-level analyses when trying to improve our understanding of sexual well-being in older adults. While the use of dyadic analytic approaches is now common in relationship research, it is largely absent from the assessment of sexuality and sexual well-being among older men and women.

\section{Current study}

To the best of our knowledge this is the first cross-cultural study of aging couples' sexuality that uses a dyadic approach. The study had two aims: (1) to further validate a 5-dimensional measure of sexual well-being that was recently developed in a large-scale non-dyadic sample from four European countries (Træen et al. 2018) and (2) to explore the structure of associations among older couples' emotional intimacy, frequency of sexual intercourse, and sexual well-being. Due to exploratory character of our study, no specific hypotheses were proposed.

Based on the literature on the associations between emotional closeness and sexual activity and on the advantages of using a dyadic approach (Muise et al. 2018), we tested a model in which the frequency of sexual intercourse was hypothesized to mediate the association between the couple's emotional intimacy and sexual well-being. Several points of interest were explored in the model. First, we were interested in comparing male and female partner effects. Taking into account traditional and gender-specific sexual socialization, we expected to find male partner effects more pronounced than female partner effects. Secondly, we analyzed the association between emotional intimacy and sexual well-being to add to insights about a robust link between intimacy and sexual satisfaction, particularly among aging individuals. Finally, taking into account that the central role of sexual intercourse in heterosexual relationships has been 
shown to wane with aging, we wanted to explore whether sexual activity remains a psychosocial behavioral factor underlying the relationship between emotional intimacy and sexual well-being in older couples.

\section{Method}

\section{Participants and procedures}

Data for this study were collected as part of a postal survey on sexuality among aging men and women that was carried out in four European countries (Norway, Denmark, Belgium, and Portugal) in 2016. The survey used national probabilitybased samples of men and women aged 60-75 years (Træen et al. 2018). The sample size was 1270 in Norway, 1045 in Denmark, 990 in Belgium, and 509 in Portugal, with participation rates ranging from $68.2 \%$ in Norway to $25.5 \%$ in Portugal. The notably higher non-participation rate in Portugal likely reflected lower education levels and higher traditionalism (suggested by higher religiosity observed among Portuguese participants). In this study, we only used the data from a subsample of couples, who were recruited in parallel with individual participants. All coupled participants in the targeted age range (60-75 years) who agreed to participate in the study were asked whether their partner would also like to take part. If the partner provided her/his consent, both members of the couple were mailed a questionnaire. This dyadic subsample included 218 couples in Norway, 207 in Denmark, 135 in Belgium, and in 117 Portugal.

The average age of the participants ranged from 67.7 years $(\mathrm{SD}=3.87)$ in Denmark to $65.6(\mathrm{SD}=4.18)$ in Portugal. Duration of the relationship/marriage was, similarly, the longest among Danish $(M=40.58, \mathrm{SD}=12.77)$ and the shortest among Portuguese partners $(M=30.30$, $\mathrm{SD}=17.42$ ). We observed substantial educational differences between countries (see Table 1). Couples in Norway had the highest proportion of college educated (55.1\%) and the lowest proportion of only primary-school educated partners $(9.9 \%)$. In contrast, among Portuguese couples, only $15.8 \%$ of partners reported tertiary education and $37.6 \%$ primary education.

\section{Questionnaire and measures}

After they were contacted by phone, prospective participants were sent a questionnaire through the mail (developed in English and translated into local languages by members of an international research team). Couples were asked to complete the questionnaire separately.

Following our earlier paper (Štulhofer et al. 2018), sexual well-being was operationalized as a latent construct consisting of the following five dimensions. (1) Sexual satisfaction was assessed with two related items (zero-order correlation coefficients ranged from .68 to .80 across countries): Thinking about your sex life in the last year, how satisfied are you with your sexual life? and how satisfied are you with the current level of sexual activity in your life, in a general way? Answers were recorded using a 5-point Likert-like scale. The composite variable had satisfactory reliability (Cronbach's $\alpha$ ranged from .77 to .81). (2) The frequency of cuddling and caressing was assessed by two items $(r=.46-.56)$ : Over the past 4 weeks, how often have you been sexually touched and caressed by your partner? $(1=$ not at all to $5=$ almost daily) and my partner and I kiss and cuddle each other... ( 1 = seldom, 2 = often) developed by Heiman et al. 2011. The two items were multiplied, with higher scores pointing to more frequent cuddling and caressing. (3) Sexual intimacy was measured by the following one-item indicator: I feel emotionally close to my partner when we have sex together. Responses ( $1=$ always to $5=$ hardly ever) were reverse-coded so that higher scores denote higher sexual intimacy. (4) Perceived sexual compatibility was assessed using two items from the NATSAL-SF tool (Jones et al. 2015): My partner and I share the same level of interest in having sex and my partner and I share the same sexual likes and dislikes. Responses were anchored using a Likert-type scale. The two items, which were strongly correlated across the four countries ( $r=.62-.81)$, were summed, with higher scores indicating higher sexual compatibility. Finally, (5) distress over sexual function was measured by a modified version of the NATSAL-SF (Jones et al. 2015). Participants who experienced one of more sexual difficulties in the past 12 months were asked to indicate the level of distress (ranging from $1=$ no distress to $4=$ severe distress) associated with each of eight common sexual difficulties. Distress scores were reverse-coded (higher scores point to lower levels of stress over one's sexual function) and summed into a composite indicator.

Emotional intimacy was assessed using the 5-item (e.g., I can share my deepest thoughts and feelings with this person and this person cares deeply for me) Emotional Intimacy Scale (Sinclair and Dowdy 2005), which had a high reliability in all four countries (Cronbach's $\alpha=.90-.91$ ). Scale scores were reverse-coded, so that higher scores indicate higher intimacy.

Sexual intercourse frequency (how many times have you had or attempted sexual intercourse...) in the past month was assessed by a single-item indicator measured on a 7 -point scale ranging from $1=$ none to $7=$ more than once a day. 
Table 1 Basic sociodemographic characteristics of the dyadic sample (by country)

\begin{tabular}{|c|c|c|c|c|c|c|c|c|}
\hline & \multicolumn{2}{|l|}{ Norway } & \multicolumn{2}{|l|}{ Denmark } & \multicolumn{2}{|l|}{ Belgium } & \multicolumn{2}{|l|}{ Portugal } \\
\hline & $\begin{array}{l}\text { Male partner } \\
n(\%)\end{array}$ & Female partner & $\begin{array}{l}\text { Male partner } \\
n(\%)\end{array}$ & Female partner & $\begin{array}{l}\text { Male partner } \\
n(\%)\end{array}$ & Female partner & $\begin{array}{l}\text { Male partner } \\
n(\%)\end{array}$ & Female partner \\
\hline \multicolumn{9}{|l|}{ Age } \\
\hline $60-65$ & $57(26.1)$ & $93(42.7)$ & $59(28.5)$ & $78(37.7)$ & $38(28.1)$ & $66(48.9)$ & $50(42.7)$ & $72(61.5)$ \\
\hline $66-70$ & $85(39.0)$ & $86(39.4)$ & $73(35.3)$ & $90(43.5)$ & $60(44.4)$ & $48(35.6)$ & $42(35.9)$ & $35(29.9)$ \\
\hline $71-75$ & $76(34.9)$ & $39(17.9)$ & $75(36.2)$ & $39(18.8)$ & $37(27.4)$ & $21(15.6)$ & $25(21.4)$ & $10(8.5)$ \\
\hline \multicolumn{9}{|l|}{ Education } \\
\hline Primary & $26(11.9)$ & $17(7.8)$ & $59(28.9)$ & $50(24.3)$ & $17(15.6)$ & $25(18.6)$ & $38(32.5)$ & $50(42.7)$ \\
\hline Secondary & $65(29.8)$ & $87(40.1)$ & $72(35.3)$ & $79(38.3)$ & $72(50.3)$ & $71(52.9)$ & $62(53.0)$ & $47(40.2)$ \\
\hline Tertiary & $127(58.3)$ & $113(52.1)$ & $73(35.8)$ & $77(37.4)$ & $46(34.1)$ & $38(28.4)$ & $17(14.5)$ & $20(17.1)$ \\
\hline \multicolumn{9}{|c|}{ Relationship duration } \\
\hline$\leq 10$ years & $26(6.6)$ & & $26(6.5)$ & & $26(10.2)$ & & $46(22.1)$ & \\
\hline $11-20$ years & $28(7.1)$ & & $10(2.5)$ & & $6(2.3)$ & & $8(3.8)$ & \\
\hline $21-30$ years & $34(8.6)$ & & $24(6.0)$ & & $12(4.7)$ & & $18(8.7)$ & \\
\hline$\geq 31$ years & 306 (77.7) & & 338 (84.9) & & $164(82.8)$ & & $136(65.4)$ & \\
\hline \multicolumn{9}{|c|}{ Religious attendance } \\
\hline Never & $78(35.9)$ & $66(30.7)$ & $65(31.9)$ & $52(2541)$ & $50(37.0)$ & $51(38.9)$ & $29(25.4)$ & $23(20.2)$ \\
\hline $\begin{array}{l}\text { Less than once } \\
\text { a year }\end{array}$ & $50(23.0)$ & 47 (21.9) & $50(24.5)$ & $54(26.3)$ & $21(15.6)$ & $11(8.4)$ & $18(15.8)$ & $14(12.3)$ \\
\hline $\begin{array}{l}\text { Once or twice a } \\
\text { year }\end{array}$ & $62(28.6)$ & $71(33.0)$ & 65 (31.9) & 67 (32.7) & $33(24.4)$ & $41(31.3)$ & $32(28.1)$ & $22(19.3)$ \\
\hline $\begin{array}{l}\text { On a monthly } \\
\text { basis }\end{array}$ & $16(7.4)$ & $21(9.8)$ & $19(9.3)$ & $27(13.2)$ & $22(16.3)$ & $19(16.0)$ & $19(16.7)$ & $28(24.6)$ \\
\hline $\begin{array}{l}\text { Once a week or } \\
\text { more often }\end{array}$ & $11(5.1)$ & $10(4.7)$ & $5(2.5)$ & $5(2.4)$ & $9(6.7)$ & $7(5.3)$ & $16(14.0)$ & $27(23.7)$ \\
\hline \multicolumn{9}{|l|}{ Place of residence } \\
\hline Village & $138(31.7)$ & & $162(39.5)$ & & $60(23.1)$ & & $22(9.6)$ & \\
\hline Small town & $162(37.2)$ & & $134(32.7)$ & & $140(53.8)$ & & $60(26.3)$ & \\
\hline $\begin{array}{l}\text { Medium-sized } \\
\text { town }\end{array}$ & $48(11.0)$ & & $56(13.7)$ & & $36(13.8)$ & & $44(19.3)$ & \\
\hline $\begin{array}{c}\text { Suburb of a } \\
\text { large city }\end{array}$ & $38(8.7)$ & & $40(9.8)$ & & $16(6.2)$ & & $34(14.9)$ & \\
\hline $\begin{array}{l}\text { Metropolitan } \\
\text { city }\end{array}$ & $50(11.5)$ & & $18(4.4)$ & & $8(3.1)$ & & $68(29.8)$ & \\
\hline
\end{tabular}

\section{Statistical analysis}

Dyadic data are characterized by non-independence of partners' responses (partners are nested within couples) reflecting the shared reality of living together-which, if not taken into account, results in biased estimates due to underestimated standard errors. The most common approach to dyadic analysis, the Actor-Partner Independence Model (APIM; Kenny et al. 2006; Muise et al. 2018), enables the distinction between actor effects, or associations between actor's characteristics (e.g., the relationship between a person's beliefs about his/her aging body and sexual satisfaction), and partner effects, or associations between actor's and his/her partner's characteristics (e.g., the relationship between the person's beliefs about his/ her aging body and his/her partner's sexual satisfaction). Although APIM can be implemented using various statistical techniques, the current study employed structural equation modeling approach to estimate direct and indirect actor- and partner-specific effects of emotional intimacy on sexual well-being.

Using confirmatory factor analysis (CFA), we first reassessed the 5-dimensional model of sexual well-being developed in the non-dyadic sample (Stulhofer et al. 2018). Model fit was evaluated by the comparative fit index (CFI) values $\geq .90$ (acceptable fit) or $\geq .95$ (excellent fit) and the RMSEA index of parsimony values $\leq .05$ (excellent fit) or $\leq .08$ (acceptable fit) (Byrne 2010). Next, we tested the model's measurement invariance across countries. Fit of the multigroup baseline or unconstrained model was compared to 
progressively more constrained models representing metric and scalar invariance (van de Schoot et al. 2012). Standard Chi-square difference test and CFI difference test $(\Delta \mathrm{CFI})$, which is insensitive to sample size, were used for model comparisons; values $\leq .002$ indicated indistinguishable fit. At least partial scalar invariance was required to justify between-countries comparisons (Bryne et al. 1998). In the final step, the full APIM mediation model was explored separately for each country. Following Shrout and Bolger (2002), mediation was assessed by inspecting bootstrapped 95\% confidence intervals around total and specific indirect effects (in the case when both actor- and partner-specific mediation is present). Mediation is significant if lower and upper bounds are either below or above zero.

All analyses were carried out using the IBM AMOS 22 statistical software package. Except for mediation testing (cases with missing values were omitted to enable bootstrapping with 1000 resamples), missing information was estimated using the model-based full information maximum likelihood (FIML) approach (Graham 2012; Arbuckle 2013).

\section{Results}

Sociodemographic characteristics of the sample are presented in Table 1. Couples' age and relationship duration were the highest in Denmark and the lowest in Portugal (Kruskal-Wallis $H=26.54, p<.001$ and $H=41.01, p<.001$, respectively). On average, Danish couples reported being together for 40.6 years, while Portuguese couples reported mean relationship duration of about 30 years. Education levels were the highest in the Norwegian sample and the lowest in the Portuguese sample $(H=82.40, p<.001)$. The opposite ranking was found in the case of religiosity, as Portuguese couples reported the highest and Norwegian couples the lowest frequency of attending religious ceremonies $(H=14.40, p<.01)$. Finally, a large urban residence was most frequent in the Portuguese sample and least frequent in the Danish samples $(H=68.51, p<.001)$.

Means and standard deviations of the key indicators by country and partner are shown in Table 2. Dyadic associations in reported levels emotional intimacy, which ranged from .85 in the Norwegian couples and .62 in the Belgian couples, were systematically stronger than associations in reported frequency of sexual intercourse $(r=.52-.34)$. Latent means of sexual well-being were consistently higher in male compared to female partners, but the difference

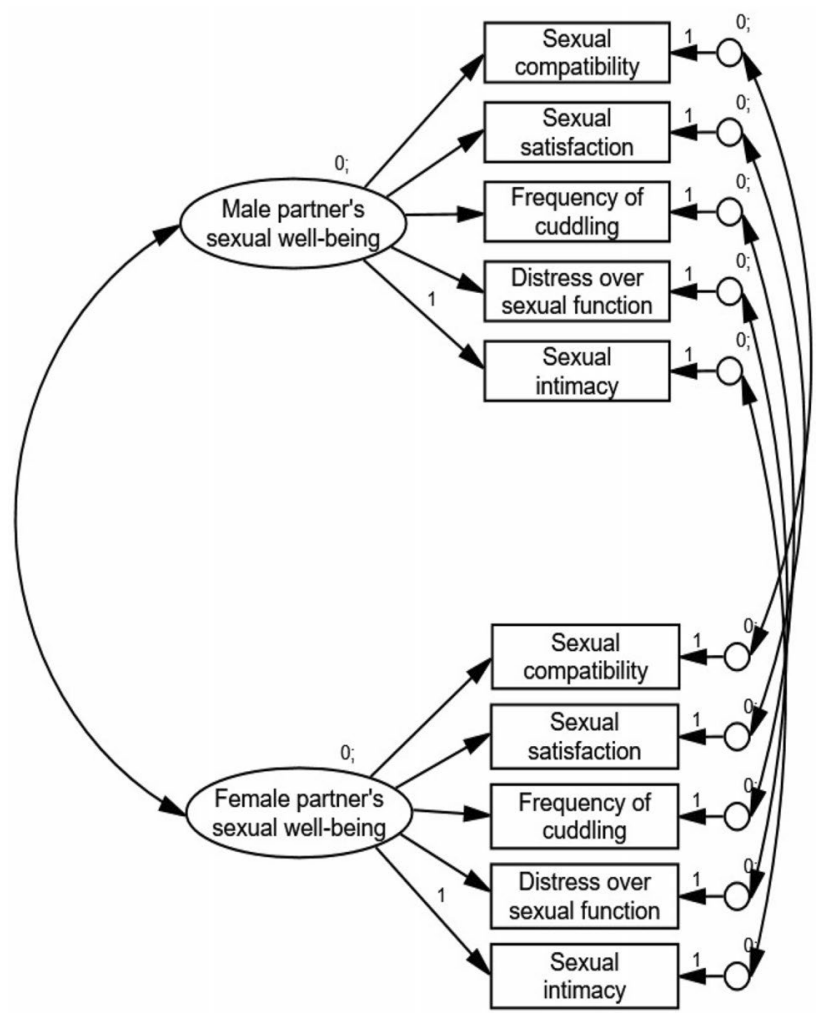

Fig. 1 The model of couple's sexual well-being

Table 2 Means and standard deviations of the key indicators by country and partner

\begin{tabular}{|c|c|c|c|c|c|c|c|c|}
\hline & \multicolumn{2}{|l|}{ Norway } & \multicolumn{2}{|l|}{ Denmark } & \multicolumn{2}{|l|}{ Belgium } & \multicolumn{2}{|l|}{ Portugal } \\
\hline & $\begin{array}{l}\text { Male partner } \\
M(\mathrm{SD})\end{array}$ & Female partner & $\begin{array}{l}\text { Male partner } \\
M(\mathrm{SD})\end{array}$ & Female partner & $\begin{array}{l}\text { Male partner } \\
M(\mathrm{SD})\end{array}$ & Female partner & $\begin{array}{l}\text { Male partner } \\
M(\mathrm{SD})\end{array}$ & Female partner \\
\hline $\begin{array}{l}\text { Emotional inti- } \\
\text { macy }\end{array}$ & $1.71(.61)$ & $1.69(.66)$ & $1.68(.63)$ & $1.66(.64)$ & $1.79(.67)$ & $1.75(.71)$ & $1.68(.66)$ & $1.72(.77)$ \\
\hline \multirow{2}{*}{$\begin{array}{l}\text { Frequency of } \\
\text { sexual inter- } \\
\text { course }\end{array}$} & $2.78(1.43)$ & $2.74(1.36)$ & $2.66(1.35)$ & $2.55(1.39)$ & $2.60(1.30)$ & $2.43(1.33)$ & $3.06(1.41)$ & $2.80(1.45)$ \\
\hline & $M(\mathrm{SE})$ & & $M(\mathrm{SE})$ & & $M(\mathrm{SE})$ & & $M(\mathrm{SE})$ & \\
\hline Sexual well-being & $4.60(.05)$ & $4.48(.05)$ & $4.59(.06)$ & $4.46(.08)$ & $4.38(.08)$ & $4.33(.08)$ & $4.40(.09)$ & $4.30(.09)$ \\
\hline
\end{tabular}


reached statistical significance only the largest, Norwegian sample $(p<.05)$.

\section{Successful well-being model}

Figure 1 shows the model of well-being, developed in our earlier paper (Štulhofer et al. 2018), that was explored here using dyadic data. The findings of APIM-based CFA suggested that the model fitted the data well $\left(\chi_{(29)}^{2}=92.71\right.$, $\mathrm{CFI}=.959$, RMSEA $=.057)$. To test for measurement invariance, the baseline (unconstrained) multi-group model $\left(\chi_{(116)}^{2}=195.53, \mathrm{CFI}=.951, \mathrm{RMSEA}=.032\right)$, with countries as groups, was compared to progressively more constrained models that reflected metric and scalar invariance. After factor loadings for distress about sexual function were allowed to vary by country, partial metric invariance was attained $\left(\chi_{(128)}^{2}=207.39, \mathrm{CFI}=.951, \mathrm{RMSEA}=.030\right.$; cf. Table 3$)$, which confirmed the model's conceptual validity for dyads in all four countries. Given that the levels (i.e., intercepts) of underlying items were country-specific, direct cross-cultural comparisons of the associations among key constructs were not warranted.

\section{Emotional intimacy, frequency of sexual intercourse, and sexual well-being}

The structure of associations among the key constructs was explored using path analytic APIM with two manifest variables (emotional intimacy and frequency of sexual intercourse) and one latent variable (sexual well-being). Using this model, we tested whether the frequency of sexual intercourse mediated the association between partners' emotional intimacy and their sexual well-being. After the initial model failed to reach acceptable fit $\left(\chi_{(65)}^{2}=389.61, \mathrm{CFI}=.898\right.$, RMSEA =.086), modification indices were inspected for suggestions about improving fit. Allowing errors of sexual satisfaction and distress over sexual function items to covary (it is highly plausible that distress caused by a sexual

Table 3 Model fit and invariance evaluation information

\begin{tabular}{|c|c|c|c|c|c|}
\hline & $\chi^{2}(\mathrm{df})$ & CFI & $\Delta \mathrm{CFI}$ & RMSEA & $\begin{array}{l}\text { RMSEA } \\
90 \% \mathrm{CI}^{\mathrm{a}}\end{array}$ \\
\hline Total sample & $92.71(29)$ & .959 & & .057 & $.044-.070$ \\
\hline $\begin{array}{l}\text { Multi-group } \\
\text { model by } \\
\text { country, } \\
\text { unconstrained }\end{array}$ & 195.53 (116) & .951 & & .032 & $.024-.040$ \\
\hline $\begin{array}{l}\text { Multi-group } \\
\text { model, partial } \\
\text { metric invari- } \\
\text { ance }\end{array}$ & 207.39 (129) & .951 & .000 & .030 & $.023-.038$ \\
\hline
\end{tabular}

${ }^{\mathrm{a}}$ Confidence interval problem would directly affect sexual satisfaction) improved fit: $\chi_{(63)}^{2}=322.00, \mathrm{CFI}=.919$, RMSEA $=.078$. An additional model respecification entailed trimming four nonsignificant paths: (1) female partner's emotional intimacy to male partner sexual well-being, (2) female partner's frequency of sex to male partner's well-being, (3) female partner's intimacy to male partner's frequency of sex, and (4) male partner's frequency of sex to female partner's sexual well-being. Compared to the full model, this more parsimonious model (see Fig. 2) fitted the data equally well $(\Delta \mathrm{CFI}=.002)$. The trimmed model explained $72-74 \%$ of variance in Norwegian, 69-70\% in Danish, 75-77\% in Belgian, and 58-63\% in Portuguese couples' well-being.

\section{Culture-specific associations and indirect effects}

The final, trimmed model was estimated separately for each country to explore actor-partner structural associations and the mediating role of the frequency of sexual intercourse. Relevant actor and partner direct effects (female partner's effects on her male partner's frequency of sexual intercourse and sexual well-being were insignificant and thus trimmed across countries), as well as indirect effects (actor- and partner-specific mediation), are presented in Table 4. In the Norwegian sample, all direct effects were significant, except for the association between male partner's emotional intimacy and the frequency of sex reported by his female partner. Among Norwegian men, coital frequency substantially mediated the association between emotional intimacy and sexual well-being. In their female partners, we observed two specific mediation pathways (actor- and male partnerspecific indirect effects). Subsequent testing indicated that the two specific indirect effects were of similar size.

Direct effects for Danish couples were similar to the Norwegian sample, with one important exception. The association between male partner's intimacy and his reported frequency of sexual intercourse was nonsignificant. No indirect effects of coital frequency were observed. Belgian couples differed from Danish in that the levels of female partners' emotional intimacy did not predict her reported coital frequency. We observed significant partner-specific indirect effects in Belgian couples, with coital frequency mediating the association between male partner's emotional intimacy and female partner's sexual well-being.

In the Portuguese sample, we found no significant partner effects. Male partner's reported intimacy did not predict either his female partner reported coital frequency or her sexual well-being-unlike in the other three countries. Actor effects, however, were significant in both genders. Frequency of sexual intercourse significantly mediated the relationship between emotional intimacy and sexual well-being only in male partners. The size of this indirect effect was substantially smaller than observed among Norwegian men. 


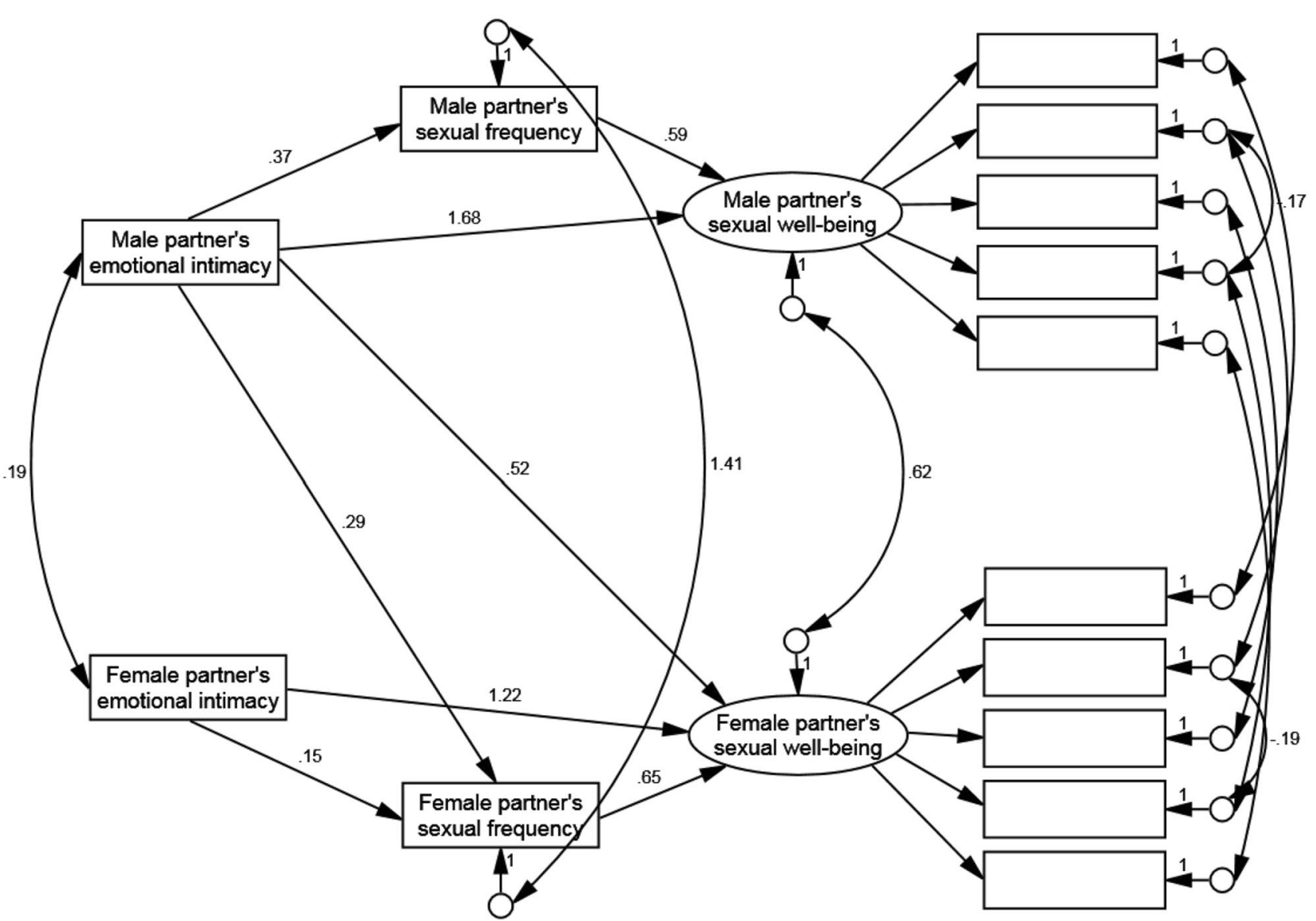

Fig. 2 Final path analytic actor-partner interdependence model $(n=677)$. Notes: all paths (unstandardized path coefficients are presented) and structural covariances significant at $p<.05$

Table 4 Associations among emotional intimacy, frequency of sexual intercourse, and sexual well-being in couples from four European countries (path analytic APIM)

\begin{tabular}{|c|c|c|c|c|}
\hline & $\begin{array}{l}\text { Norway } \\
\text { B (SE) }\end{array}$ & $\begin{array}{l}\text { Denmark } \\
\text { B (SE) }\end{array}$ & $\begin{array}{l}\text { Belgium } \\
\text { B (SE) }\end{array}$ & $\begin{array}{l}\text { Portugal } \\
\text { B (SE) }\end{array}$ \\
\hline Male intimacy to male sexual well-being & $1.45 * * *(.22)$ & $1.91 * * *(.24)$ & $2.71 * * *(.48)$ & $1.39 * * *(.24)$ \\
\hline $\begin{array}{l}\text { Male intimacy to male frequency of sexual inter- } \\
\text { course }\end{array}$ & $.59 * * *(.16)$ & $.24(.15)$ & $.13(.17)$ & $.59 * *(.20)$ \\
\hline $\begin{array}{l}\text { Male frequency of sexual intercourse to male } \\
\text { sexual well-being }\end{array}$ & $.87 * * *(.16)$ & $.59 * * *(.09)$ & $.34 * *(.11)$ & $.48 * * *(.20)$ \\
\hline $\begin{array}{l}\text { Male intimacy to female frequency of sexual } \\
\text { intercourse }\end{array}$ & $.30(.16)$ & $.23(.16)$ & $.33(.18)$ & $.29(.22)$ \\
\hline Male intimacy to female sexual well-being & $.54 * *(.20)$ & $.83 * * *(.20)$ & $.75 * *(.27)$ & $.01(.22)$ \\
\hline Female intimacy to female sexual well-being & $1.16^{* * *}(.19)$ & $1.21 * * *(.20)$ & $1.85 * * *(.35)$ & $1.41 * * *(.21)$ \\
\hline $\begin{array}{l}\text { Female intimacy to female frequency of sexual } \\
\text { intercourse }\end{array}$ & $.19 *(.09)$ & $.20 *(.10)$ & $.18(.13)$ & $.11(.14)$ \\
\hline \multirow{2}{*}{$\begin{array}{l}\text { Female frequency of sexual intercourse to female } \\
\text { sexual well-being }\end{array}$} & $.82 * * *(.10)$ & $.71 * * *(.10)$ & $.49 * * *(.13)$ & $.55 * * *(.10)$ \\
\hline & Indirect effect $95 \% \mathrm{CI}$ & Indirect effect $95 \% \mathrm{CI}$ & Indirect effect $95 \% \mathrm{CI}$ & Indirect effect $95 \% \mathrm{CI}$ \\
\hline Male intimacy to male sexual well-being & $.51(.31-.78)^{* *}$ & $.14(-.02$ to .31$)$ & $.05(-.03$ to .31$)$ & $.28(.12-.57)^{* *}$ \\
\hline Female intimacy to female sexual well-being & $.16(.04-.28)^{*}$ & $.14(.00-.28)$ & $.09(-.02$ to .36$)$ & $.06(-.07$ to .18$)$ \\
\hline Male intimacy to female sexual well-being & $.25(.06-.46)^{*}$ & $.16(-.02$ to .37$)$ & $.16(.03-.48) *$ & $.16(-.03$ to .42$)$ \\
\hline
\end{tabular}

$* p<.05, * * p<.01, * * * p<.001$ 
Across countries, effect sizes for the association between actor's intimacy and coital frequency were higher among male than female partners. In contrast, the association between actor's frequency of sexual intercourse and sexual well-being was similarly strong in both genders.

The proportion of variance in male sexual well-being explained by the APIM model (Fig. 2) ranged from 55\% in Portugal to $78 \%$ in Norway. In female participants, the explained variance in sexual well-being ranged from $63 \%$ in Portugal to $75 \%$ in Belgium.

\section{Discussion}

To fill a gap in research on aging couples' sexuality, this cross-cultural study used a dyadic approach to investigate the connections among emotional intimacy, frequency of sexual intercourse, and sexual well-being. The study had two specific aims. First, we wished to extend previous validation of the 5-dimensional model of aging individuals' sexual well-being (Štulhofer et al. 2018) using cross-cultural dyadic data. Secondly, we aimed to explore the association between couples' emotional intimacy and sexual well-being, and the mediating role of the frequency of sexual intercourse. Unlike intimacy, the role of sexual frequency has been unclear, if not ambiguous, in the context of aging individuals' sexuality (Sandberg 2013; Müller et al. 2014; Lee et al. 2016; Fileborn et al. 2017).

In regard to the overall structure of relationships among emotional intimacy, sexual activity, and sexual well-being, country-by-country structural equation APIM analyses pointed to a number of consistent and significant actor effects. For example, intimacy and frequency of sexual intercourse predicted both male and female partners' sexual well-being. Partner effects were notably weaker and genderspecific. Female partners' emotional intimacy did not predict their male partners' frequency of sex and sexual well-being. In contrast, male partners' intimacy significantly predicted female partners' sexual well-being in three of the four countries. The relationship was nonsignificant in the most religious and least educated sample in this study (Portugal).

Marked gender-specific differences in partner effects found in this study need to be considered in the context of a more traditional gender role socialization and social regulation of sexuality which was common at the time our participants were emerging adults (see Francoeur and Noonan 2004; Herzog 2011). When thinking about more traditional gender roles, which regard "emotion work" as mostly women's responsibility (men are, instead, expected to control their feelings (Brody and Hall 2008; Fahs and Swank 2016)), it may be surprising that men's but not women's reports of intimacy were predictive of the other partner's sexual well-being. However, this is not incompatible with traditional gender roles. Male emotional intimacy may be valued highly precisely because, at least in its expression, it is less frequent than female emotional intimacy. Also, partner variables (including intimacy) seem more systematically related to female than male sexuality, even on a daily basis (see Dewitte and Mayer 2018), although it is unclear to what extent this applies to different age groups.

We also explored whether the frequency of sexual intercourse mediated the link between emotional intimacy on sexual well-being. We recognize the possibility that emotional intimacy could mediate the association between sexual activity and sexual well-being, but given that the tendency to have sex for physical and utilitarian motives seems to decrease with increasing age (e.g., Wyverkens et al. 2018), we were more interested in exploring models that take emotional intimacy as a starting point. Moreover, although the degree of intimacy experienced during sexual activity can be expected to vary (within and between individuals) and this in itself could influence sexual well-being, we measured emotional intimacy at a more global level. For these reasons, we considered it both more relevant and more interesting to explore the degree to which it might influence sexual activity and, indirectly, sexual well-being.

This mediation model was supported in male partners from Norway and Portugal, as well as in female partners from Norway and Belgium. The actor-specific indirect effects were notably stronger in male compared to female partners, suggesting that the frequency of sexual intercourse plays a more important role for older coupled men's than women's sexual well-being. For example, the mediation was about twice as strong in Norwegian men than their female partners. Partner-specific indirect effects, where male partner's emotional intimacy contributed to his female partner's sexual well-being through more frequent sex, were observed only in female Norwegian participants. Whether the fact that this indirect effect was found only in Norway can be attributed to a high level of gender equality achieved in this country or to some other culture-specific characteristics that were not assessed in this study is unclear.

This study's findings provided additional support for the validity of the sexual well-being model, as applied to aging couples. Although the overall structure of the model did not differ among countries, differences were found in mean levels of various facets of sexual well-being, which suggested some culture-specific influences on aging couples' sexual well-being to be explored in future research. Interestingly, distress about one or more sexual difficulties was consistently higher among older women than men in the four countries (not presented in tables), which is consistent with findings in younger samples (Fugl-Meyer and Fugl-Meyer 1999; Hendrickx et al. 2014). For example, in a sample of 
35,132 Flemish heterosexual men and women (mean age was 39 years), Hendrickx et al. (2014) found that $20 \%$ of women and $11 \%$ of men reported at least one distressful sexual difficulty.

Taking into account its robust cross-cultural performance, our 5-dimensional model of sexual well-being may be a useful tool in clinical and non-clinical studies of older individuals' and couples' sexuality and sexual health. If our composite indicator of distress over sexual function (the original distress items were sexual difficulty-specific) is replaced with a general single-item indicator, which is the standard practice in large-scale sexological studies (e.g., Jones et al. 2015), the sexual well-being measure would be represented by only eight items in total, which most surveys-including those that do not focus on sexual aspects of aging - would not have a problem accommodating. Apart from being practical to use, this newly developed sexual well-being measure might provide insight into components of and processes that underlie sexual well-being in older individuals and couples, including in longitudinal studies. In clinical settings, our measure might assist in identifying and addressing particular individual emotional and erotic needs, as well as shortcomings in the couple's habitual sexual "choreography."

\section{Study limitations}

The cross-sectional nature of our study does not warrant any discussion about causal links. The direction of paths in the structural mediation model was assumed, based on our conceptual framework, and not empirically determined. The relationship between the constructs might go in either direction, including a number of likely bidirectional ties. Our study recruitment presents another limitation. Sexually active couples, as well as those with more liberal views about sexuality, were likely oversampled at the expense of sexually inactive and more traditional (possibly more religious) couples. Taking into account country-specific participation rates and proportion of participants living in (usually more liberal) large urban settings, such bias was probably most substantial in the case of Portugal. Overall, this substantially limits the generalizability of our findings. Despite the robustness of APIM estimations, the country samples (especially the Portuguese) were underpowered when associations were small. This limitation needs to be considered particularly when partner effects are addressed. Finally, although the structure and levels of sexual well-being differ in heterosexual and non-heterosexual couples, the fact that only one person in our overall sample identified as gay or lesbian, while three others reported that they were bisexual (an additional 17 checked the category "other") precluded any meaningful statistical treatment of sexual orientation.

\section{Conclusions and implications}

This dyadic study aimed to contribute to an emerging interest in positive aspects of sexual aging. Apart from providing additional cross-cultural validation of a newly developed measure of sexual well-being, which suggested some unmeasured culture-specific influences, we observed consistent associations among emotional intimacy, frequency of sexual intercourse, and sexual well-being separately for both men and women. In contrast to these actor effects, partner effects were inconsistent and gender-specific (i.e., the absence of female-to-male partner influence), pointing to a likely role of more traditional gender role socialization that may have been the norm at the time our participants were growing up. As emphasized in a recent review of research on sexuality in older age (Træen et al. 2017), the field may greatly benefit from comparative research into the role of sociocultural norms and beliefs on sexual functioning and sexual well-being of older people.

Finally, our study has a couple of clinical implications. Older couples' emotional intimacy, particularly when expressed by the male partner, was found to play an important role in both partners' sexual well-being. Whether this is an age-dependent process, whereby aging moderates (particularly in men?) the strength of the association between emotional closeness and sexual well-being, is unclear and requires additional research. In addition, sexual intercourse, which likely occupies a less central place in older couples' sexual repertoire compared to younger couples, remains an independent contributor to both female and male sexual well-being. This needs to be considered when working with couples characterized by sexual health problems, as professional assistance in redefining the couple's notion of sex may be needed.

Acknowledgements This research was fully financed by the Norwegian Research Council under the Grant Number 250637.

\section{References}

Abraham L, Symonds T, Morris MF (2008) Psychometric validation of a sexual quality of life questionnaire for use in men with premature ejaculation or erectile dysfunction. J Sex Med 5:595-601. https://doi.org/10.1111/j.1743-6109.2007.00749.x

Anderson AB, Rosen NO, Price L, Bergeron S (2016) Associations between penetration cognitions, genital pain, and sexual well-being in women with provoked vestibulodynia. J Sex Med 13:444-452. https://doi.org/10.1016/j.jsxm.2015.12.024

Arbuckle JL (2013) IBM AMOS 22 user's guide. Amos Development Corporation, Mount Pleasant

Bancroft J, Loftus J, Long JS (2003) Distress about sex: a national survey of women in heterosexual relationships. Arch Sex Behav 32:193-208. https://doi.org/10.1023/a:1023420431760 
Bancroft J, Long JS, McCabe J (2011) Sexual well-being: a comparison of U.S. black and white women in heterosexual relationships. Arch Sex Behav 40:725-740. https://doi.org/10.1007/s 1050 8-010-9679-z

Bell S, Reissing ED, Henry LA, Van Zuylen H (2017) Sexual activity after 60: a systematic review of associated factors. Sex Med Rev 5:52-80. https://doi.org/10.1016/j.sxmr.2016.03.001

Brody LR, Hall JA (2008) Gender and emotion in context. In: Lewis M, Haviland-Jones JM, Feldman Barrett L (eds) Handbook of emotions, 3rd edn. The Guilford Press, New York, pp 395-408

Bryne BM, Shavelson RJ, Muthén B (1998) Testing for the equivalence of factor covariance and mean structure: the issue of partial measurement in variance. Psychol Bull 105:456-466. https://doi. org/10.1037/0033-2909.105.3.456

Byrne BM (2010) Structural equation modeling with AMOS: basic concepts, applications, and programming. Routledge, New York

Costa P, Arnould B, Cour F, Boyer P, Marrel A, Jaudinot EO, Solesse de Gendre A (2003) Quality of Sexual Life Questionnaire (QVS): a reliable, sensitive and reproducible instrument to assess quality of life in subjects with erectile dysfunction. Int J Impot Res 15:173-184. https://doi.org/10.1038/sj.ijir.3900995

De Visser RO, Rissel CE, Richters J, Smith AMA, De Visser RO, Rissel CE, Richters J, Smith AMA (2007) The impact of sexual coercion on psychological, physical, and sexual well-being in a representative sample of australian women. Arch Sex Behav 36:676-686. https://doi.org/10.1007/s10508-006-9129-0

DeLamater J (2012) Sexual expression in later life: a review and synthesis. J Sex Res 49:125-141. https://doi.org/10.1080/00224 499.2011.603168

Dewitte M, Mayer A (2018) Exploring the link between daily relationship quality, sexual desire, and sexual activity in couples. Arch Sex Behav 47:1675-1686. https://doi.org/10.1007/s1050 8-018-1175-x

Fahs B, Swank E (2016) The other third shift?: Women's emotion work in their sexual relationships. Fem Form 28:46-69. https:// doi.org/10.1353/ff.2016.0043

Fileborn B, Brown G, Lyons A, Hinchliff S, Heywood W, Minichiello V, Malta S, Barrett C, Crameri P (2017) Safer sex in later life: qualitative interviews with older Australians on their understandings and practices of safer sex. J Sex Res 4499:1-14. https://doi. org/10.1080/00224499.2017.1280121

Fisher L, Anderson GO, Chapagain M, Mentenegro X, Smoot J, Takalkar A (2010) Sex, romance, and relationships: AARP Survey of Midlife and Older Adults. Washington, DC

Francoeur RT, Noonan RJ (2004) The continuum complete international encyclopedia of sexuality. Continuum, New York

Freak-Poli R, Kirkman M, De Castro Lima G, Direk N, Franco OH, Tiemeier H (2017) Sexual activity and physical tenderness in older adults: cross-sectional prevalence and associated characteristics. J Sex Med 14:918-927. https://doi.org/10.1016/j. jsxm.2017.05.010

Fugl-Meyer AR, Fugl-Meyer LS (1999) Sexual disabilities, problems and satisfaction in 18-74 year old Swedes. Scand J Sexol 2:79-105

Graf AS, Patrick JH (2014) The influence of sexual attitudes on midto late-life sexual well-being: age, not gender, as a salient factor. Int J Aging Hum Dev 79:55-79. https://doi.org/10.2190/ag.79.1.c

Graham JW (2012) Missing data: analysis and design. Springer, New York

Heiman JR, Long JS, Smith SN, Fisher WA, Sand MS, Rosen RC (2011) Sexual satisfaction and relationship happiness in midlife and older couples in five countries. Arch Sex Behav 40:741-753. https://doi.org/10.1007/s10508-010-9703-3

Hendrickx L, Gijs L, Enzlin P (2014) Prevalence rates of sexual difficulties and associated distress in heterosexual men and women: results from an internet survey in Flanders. J Sex Res 51:1-12. https://doi.org/10.1080/00224499.2013.819065
Hendrickx L, Gijs L, Enzlin P (2015) Age-related prevalence rates of sexual difficulties, sexual dysfunctions, and sexual distress in heterosexual women: results from an online survey in Flanders. $\mathbf{J}$ Sex Med 12:424-435. https://doi.org/10.1111/jsm.12725

Herzog D (2011) Sexuality in Europe : a twentieth-century history. Cambridge University Press, Cambridge

Janssen E, McBride KR, Yarber W, Hill BJ, Butler SM (2008) Factors that influence sexual arousal in men: a focus group study. Arch Sex Behav 37:252-265. https://doi.org/10.1007/s1050 8-007-9245-5

Jones KG, Mitchell KR, Ploubidis GB, Wellings K, Datta J, Johnson AM, Mercer CH (2015) The Natsal-SF measure of sexual function: comparison of three scoring methods. J Sex Res 52:640 646. https://doi.org/10.1080/00224499.2014.985813

Kenny DA, Kashy DA, Cook WL (2006) Dyadic data analysis. Guilford Press, New Year

Kleinstäuber M (2017) Factors associated with sexual health and well being in older adulthood. Curr Opin Psychiatry 30:358368. https://doi.org/10.1097/yco.0000000000000354

Laumann EO, Paik A, Glasser DB, Kang J-H, Wang T, Levinson B, Moreira ED, Nicolosi A, Gingell C (2006) A Cross-national study of subjective sexual well-being among older women and men: findings from the global study of sexual attitudes and behaviors. Arch Sex Behav 35:145-161. https://doi.org/10.1007/ s10508-005-9005-3

Lee DM, Nazroo J, O'Connor DB, Blake M, Pendleton N (2016) Sexual health and well-being among older men and women in England: findings from the English longitudinal study of ageing. Arch Sex Behav 45:133-144. https://doi.org/10.1007/s1050 8-014-0465-1

Lindau ST, Schumm LP, Laumann EO, Levinson W, O'Muircheartaigh CA, Waite LJ (2007) A study of sexuality and health among older adults in the United States. N Engl J Med 357:762-774. https://doi.org/10.1056/nejmoa067423

Ménard AD, Kleinplatz PJ, Rosen L, Lawless S, Paradis N, Campbell M, Huber JD (2015) Individual and relational contributors to optimal sexual experiences in older men and women. Sex Relatsh Ther 30:78-93. https://doi.org/10.1080/14681 994.2014.931689

Mitchell KR, Mercer CH, Ploubidis GB, Jones KG, Datta J, Field N, Copas AJ, Tanton C, Erens B, Sonnenberg P, Clifton S, Macdowall W, Phelps A, Johnson AM, Wellings K (2013) Sexual function in Britain: findings from the third National Survey of Sexual Attitudes and Lifestyles (Natsal-3). Lancet 382:1817-1829. https ://doi.org/10.1016/s0140-6736(13)62366-1

Muise A, Preyde M, Maitland SB, Milhausen RR (2010) Sexual identity and sexual well-being in female heterosexual university students. Arch Sex Behav 39:915-925. https://doi.org/10.1007/s1050 8-009-9492-8

Muise A, Maxwell JA, Impett EA (2018) What theories and methods from relationship research can contribute to sex research. J Sex Res 55:540-562. https://doi.org/10.1080/00224499.2017.1421608

Müller B, Nienaber CA, Reis O, Kropp P, Meyer W (2014) Sexuality and affection among elderly German men and women in long-term relationships: results of a prospective populationbased study. PLoS ONE 9:e111404. https://doi.org/10.1371/journ al.pone. 0111404

Murray SH, Milhausen RR, Graham CA, Kuczynski L (2017) A qualitative exploration of factors that affect sexual desire among men aged 30 to 65 in long-term relationships. J Sex Res 54:319-330. https://doi.org/10.1080/00224499.2016.1168352

Neto F (2012) The satisfaction with sex life scale. Meas Eval Couns Dev 45:18-31. https://doi.org/10.1177/0748175611422898

Öberg K, Fugl-Meyer KS, Fugl-Meyer AR (2002) On sexual well-being in sexually abused Swedish women: Epidemiological aspects. Sex 
Relatsh Ther 17:329-341. https://doi.org/10.1080/1468199021 000017182

Pascoal PM, de Narciso ISB, Pereira NM (2014) What is sexual satisfaction? Thematic analysis of lay people's definitions. J Sex Res 51:22-30. https://doi.org/10.1080/00224499.2013.815149

Peixoto MM, Nobre P (2015) Prevalence and sociodemographic predictors of sexual problems in Portugal: a population-based study with women aged 18 to 79 years. J Sex Marital Ther 41:169-180. https://doi.org/10.1080/0092623x.2013.842195

Rosen RC, Bachmann GA (2008) Sexual well-being, happiness, and satisfaction, in women: the case for a new conceptual paradigm. J Sex Marital Ther 34:291-307. https://doi.org/10.1080/00926 230802096283

Rosen RC, Bachmann GA, Reese JB, Gentner L, Leiblum S, Wajszczuk C, Wanser R (2009) Female sexual well-being scale (FSWB Scale): development and psychometric validation in sexually functional women. J Sex Med 6:1297-1305. https://doi.org/10. 1111/j.1743-6109.2009.01240.x

Sandberg L (2013) Just feeling a naked body close to you: men, sexuality and intimacy in later life. Sexualities 16:261-282. https://doi. org/10.1177/1363460713481726

Santos-Iglesias P, Byers ES, Moglia R (2016) Sexual well-being of older men and women. Can J Hum Sex 25:86-98. https://doi. org/10.3138/cjhs.252-a4

Shrout PE, Bolger N (2002) Mediation in experimental and nonexperimental studies: new procedures and recommendations mediation in experimental and nonexperimental studies: new procedures and recommendations. Psychol Methods 7:422-445. https://doi. org/10.1037/1082-989x.7.4.422

Sinclair VG, Dowdy SW (2005) Development and validation of the emotional intimacy scale. J Nurs Meas 13:193-206

Stephenson KR, Meston CM, Rosen R, Derogatis L, Fourcroy J, FuglMeyer K, Lu T, Lu M, Liu V (2010) Differentiating components of sexual well-being in women: are sexual satisfaction and sexual distress independent constructs? J Sex Med 7:2458-2468. https ://doi.org/10.1111/j.1743-6109.2010.01836.x

Štulhofer A, Jurin T, Graham C, Enzlin P, Træen B (2018) Sexual wellbeing in older men and women: construction and validation of a multi-dimensional measure of four European countries. J Happiness Stud. https://doi.org/10.1007/s10902-018-0049-1
Syme ML, Cohn TJ, Stoffregen S, Kaempfe H, Schippers D (2018) "At my age...": defining sexual wellness in mid- and later life. J Sex Res. https://doi.org/10.1080/00224499.2018.1456510

Træen B, Hald GM, Graham CA, Enzlin P, Janssen E, Kvalem IL, Carvalheira A, Śtulhofer A (2017) Sexuality in older adults (65+) an overview of the literature, part 1: sexual function and its difficulties. Int J Sex Heal 29:1-10. https://doi.org/10.1080/19317 611.2016.1224286

Træen B, Štulhofer A, Janssen E, Carvalheira AA, Hald GM, Lange T, Graham C (2018) Sexual activity and sexual satisfaction among older adults in four European Countries. Arch Sex Behav. https:// doi.org/10.1007/s10508-018-1256-x

Trudel G, Dargis L, Villeneuve L, Cadieux J, Boyer R, Préville M (2014) Marital, sexual and psychological functioning of older couples living at home: the results of a national survey using longitudinal methodology (Part II). Sexologies 23:e35-e48. https:// doi.org/10.1016/j.sexol.2013.03.007

van de Schoot R, Lugtig P, Hox J (2012) A checklist for testing measurement invariance. Eur J Dev Psychol 9:486-492. https://doi. org/10.1080/17405629.2012.686740

Waite LJ, Laumann EO, Das A, Schumm LP (2009) Sexuality: measures of partnerships, practices, attitudes, and problems in the National Social Life, Health, and Aging Study. J Gerontol B Psychol Sci Soc Sci 64B:i56-i66. https://doi.org/10.1093/geron b/gbp038

Wang V, Depp CA, Ceglowski J, Thompson WK, Rock D, Jeste DV (2015) Sexual health and function in later life: a population-based study of 606 older adults with a partner. Am J Geriatr Psychiatry 23:227-233. https://doi.org/10.1016/j.jagp.2014.03.006

Wyverkens E, Dewitte M, Deschepper E, Corneillie J, Van der Bracht L, Van Regenmortel D, Van Cleempoel K, De Boose N, Prinssen P, T'Sjoen G (2018) YSEX? A replication study in different age groups. J Sex Med 15:492-501. https://doi.org/10.1016/j. jsxm.2018.02.012

Publisher's Note Springer Nature remains neutral with regard to jurisdictional claims in published maps and institutional affiliations. 